3. Cantar de mio Cid / Anónimo; edición, presentación, estudio y notas de Alberto Montaner; con un ensayo de Francisco Rico; ensayo introductorio de Margit Frenk, 2014. 1200 p. — (Clásicos de la Lengua Española)

4. Diccionario de la Real Academia Española [DRAE] [Электронный pecypc] URL: https://dle.rae.es/?w=diccionario\&origen=REDLE (дата обращения: 27.02.2021)

\title{
Осташевская Е.Ю. \\ Перцептивная лексика английского языка с семантическим компонентом «теплота» в рекламном тексте
}

Самарский государственный соџчильно-педагогический университет (Россия, Самара)

doi: 10.18411/lj-04-2021-196

\section{Аннотация}

В статье рассматриваются особенности функционирования английской перцептивной лексики с семантическим компонентом «теплота» в рекламных текстах. Используется обширный материал, представленный рекламными объявлениями различных товаров, мероприятий, услуг. На основе анализа словарных дефиниций устанавливаются значения, актуализируемые в целях создания у потребителя приятных температурных ощущений и эмоций, способствующих выполнению рекламным текстом функции воздействия и повышению его прагматического потенциала.

Ключевые слова: восприятие, температурное ощущение, реклама, воздействие, семантика, теплота

\section{Abstract}

The article examines the peculiarities of the English perceptual vocabulary with the semantic component "warmth" in advertising texts. The research involves extensive material represented by advertisements of various products, events, and services. On the basis of the analysis of dictionary definitions, the author finds out meanings that are realized in order to create pleasant temperature feelings and emotions in the consumer, which contribute to the performance of the persuasion function by the advertising text and increase its pragmatic potential. warmth

Key words: perception, temperature sensation, advertising, impact, semantics, heat,

Возникновение и развитие рекламы большинство ученых связывают с развитием массовой коммуникации, порождённой, в свою очередь, урбанизацией [1]. Среди особенностей рекламы в первую очередь отмечают ее общественный характер.

Т. Лившиц полагает, что реклама есть сообщение, целью которого является побуждение реципиента к ответным действиям [2]. Ф.Котлер считает, что реклама выполняет несколько функций: информативную, увещевательную и напоминающую [3]. Чтобы выделиться в океане рекламы, бренды создают полезный контент, отвечающий новым потребностям покупателей [4].

Определение рекламы как особого типа текстов связано со сложностями, возникающими в результате ее многоплановости и неоднозначности. Реклама, для того чтобы воздействовать, мотивировать определенное действие со стороны читателя (приобретение товара или услуги), должна передавать некое содержание, или «идею», выходящую за пределы метасемиотического уровня [5].

Как известно, основными функциями языка являются сообщение определенной информации и воздействие на адресата сообщения. Для рекламных текстов главной является функция воздействия [5], поэтому необходимо очень хорошо представлять себе потенциального покупателя, учитывать вкусы и привычки человека, чтобы 
воздействие рекламы было эффективным. Основное содержание текста во многом определено характером рекламы - ее рациональностью или эмоциональностью.

Следует, однако, иметь в виду, что деление рекламы на рациональную и эмоциональную имеет несколько искусственный характер. Так, практически все объявления, даже исключительно информативные, основанные на жесткой логике, могут вызывать проявление чувств [6].

В этой связи можно предположить, что в тексте рекламы должно содержаться большое количество языковых средств, в частности лексических единиц, эмоционально и психологически воздействующих на потенциального покупателя, на которого ориентировано конкретное рекламное сообщение.

При восприятии рекламной информации исключительно важная роль принадлежит формированию перцептивного образа товара, который оказывает самое существенное влияние на поведение покупателя. Именно поэтому маркетологи создают в рекламе образ товара, который бы вызывал положительные ощущения. Ощущение это отражение в коре головного мозга отдельных свойств предметов и явлений окружающего мира, воздействующих в данный момент на органы чувств человека. Как отмечает Е.В.Урысон, «чувства - это родовое слово для лексем зрение, слух, вкус, осязание и обоняние» [7]. Для каждого из этих видов восприятия в языке существует своя лексика, представленная различными частями речи [8]. По видам восприятие бывает: зрительное, слуховое, обонятельное, вкусовое, осязательное.

Органы восприятия и их функции представляют ту предметную область, которая, будучи лексически обозначена, входит в предмет изучения лингвистов, а лексические единицы, покрывающие этот участок внеязыковой действительности, принято называть перцептивной лексикой. Данная лексика образует в языке лексикосемантическое поле, объединённое семой «восприятие» и состоящее из пяти составляющих, каждая из которых включает единицы, отражающие один из перцептивных модусов: зрительный, слуховой, вкусовой, обонятельный, тактильный [9].

Таким образом, осязание (тактильное чувство) - одно из пяти основных видов чувств, к которым способен человек, заключающееся в способности ощущать прикосновения, воспринимать что-либо рецепторами, расположенными в коже, мышцах, слизистых оболочках.

Психологи утверждают, что мы воспринимаем ситуацию в зависимости от того, с какими предметами мы контактируем - фактура предметов, которых мы касаемся, влияет на наши суждения и поступки [10].

Учитывая значимость тактильных ощущений для человека, а также тот факт, что текст рекламы изначально нацелен на то, чтобы влиять на суждение и мысли потребителя, изучение особенностей функционирования лексики, обозначающей тактильные ощущения, в рекламном тексте представляется актуальной проблемой. При этом следует отметить, что в лингвистической литературе данная лексикосемантическая группа рассматривается в основном на материале русского языка $[9,11$, 12] и не получила достаточного освещения на материале английского языка.

По нашим наблюдениям, наиболее употребительной в тексте рекламы является лексика, передающая тактильные температурные ощущения в диапазоне тепло горячо. К ним относятся warm, warmth, warming, heat, heating, hot. Именно эти лексические единицы и составляют объект нашей работы.

Материал словарей Concise Oxford English Dictionary, www.dictionary.cambridge.org и www.macmillandictionary.com [13, 14, 15] показывает, что прилагательное warm выражает следующие значения - 1) fairly hot in a way that is comfortable and pleasant, 2) warm clothes or covers keep your body warm, 3) kind and friendly in a way that makes other people feel comfortable, 4) warm colors have red, orange, or yellow in them, 5) near the place where something is hidden 6) (of a scent or trail) fresh, 
strong; существительное warmth -два значения: 1) the feeling of heat, 2) a kind and friendly quality in someone or something; существительное warming -1) an increase in the temperature of something, 2) the process of becoming more friendly.

Англо-русский словарь Cambridge Dictionary Online и www.lingvolive.com $[14,16]$ предлагают значения слова warm: 1) тепльй; 2) тепльй, радушный; 3) тепльй (о ивете); 4) подогретый, согретый, разогретый; 5) зажиточный, хорошо устроенный; 6) близкий к иели; 7) влюбчивый 8). Существительное warmth имеет следующие русские эквиваленты: 1) тепло, теплота; 2) тепло, радушие; 3) согревание [18].

В рекламе прилагательное warm чаще всего употребляется в своем основном значении fairly hot in a way that is comfortable and pleasant:

Warm Russian Tea. (Реклама напитков в кафе, www.melskitchencafe.com)

Warm and cozy cottage for two in the mountains in Spain. (Реклама дизайна интерьера, Pufik Interiors \& Inspirations)

В рекламных текстах встречается также лексика, раскрывающая второе значение warm - warm clothes or covers to keep your body warm, которое описывает тёплые предметы гардероба.

Omni-heat: 20\% warmer. According to scientists and cold peоple. (Реклама зимней одежды Columbia)

В следующих примерах наблюдается переносное значение warm - warm colours that have red, orange, or yellow in them:

Color Trends of 2019: Warm + Creamy. (Реклама одежљы, www.beckiowens.com)

The best warm grey paint colors. (Реклама дизайна интерьера, liveonvirginiastreet.com)

В рекламе косметических средств и парфюмерии лексемы warmth, warm эксплицируют свежие, нерезкие ароматы средств по уходу за телом и лицом - то есть fresh, strong (of a scent or trail):

Warm \& cozy mist. (Реклама косметических средств PINK)

Add elements of warmth and comfort to your days with Vanilla (рекламa парфюмерной продукции Skylar)

Warm, comforting holidays scent to add to your home. (Реклама ароматизатора, @hunkerhome)

В следующих примерах актуализируется еще одно метафорическое значение warm: $a$ kind and friendly quality in someone or something

Warm glow of Christmas night. (Реклама дизайн-интерьера компании "Ella Clair \& Co.")

Mulled wine is the most soul-warming delicious drink ever (Реклама винной продукции, www.buzzfeed.com)

Warmies - cozy plush warm hugs cows, mini fully microwaveable toys (Рекламa плющевых игрушек, heat-treats.co.uk)

Здесь warm передаёт значение душевной теплоты и комфорта: тёплое сияние Рождественской ночи обозначает мягкий, приглушённый, неяркий ночной свет; согревающий душу напиток расслабляет и успокаивает; тёплые объятия мягкой плюшевой игрушки воспринимаются тактильно, но передают не температурное ощущение, а воздействуют эмоционально и создают душевный комфорт.

Производные от warm существительные warmth и warming также широко употребляются в рекламе, например:

Stop kitchen warming. (E.On - крупнейшая энергетическая компания ФРГ, которая разрабатывает «умные технологии" для обеспечения комфортной температуры в зимний и летний период). Здесь warming обозначает нежелательный перегрев помещения из-за процесса приготовления домашних блюд на кухне или внешних погодных условий и используется для указания на проблему, решить которую можно, приобретя рекламируемое оборудование. 
Лексика температурных ощущений встречается и в социальной рекламе, под которой понимается способ влияния на человека в отдельности и массы людей в целом с целью их защиты от социальных проблем и совершенствования их общественной жизни [17]. В следующих примерах warmth употреблено в рекламных объявлениях, которые призывают граждан участвовать в благотворительных проектах, таких как сбор тёплых вещей и одежды для нуждающихся.

Share the warmth. (Реклама благотворительного фонда the Winter warmth fund), (Windermere's annual coat \& blanket drive).

2019 Share the warmth: Donate a coat or blanket (Благотворительная рекламная акция организации the DAAR Community - Dulles Area Association of Realtors).

Мы полагаем, что здесь реализуются оба значения warmth, как прямое - the feeling of heat, так и переносное - a kind and friendly quality in someone or something, так как речь идет о проявлении душевной теплоты, которая заключается в пожертвовании теплых вещей для тех, кто в них нуждается.

Наиболее часто употребляемым в социальной рекламе является словосочетание global warming, под которым понимается глобальное потепление как следствие пагубного воздействия человечества на природу (an increase in the temperature of the air around the world because of pollution).(Macmillan Dictionary Online)

Global warming is leaving many homeless. (Реклама компании ECOEDUCA, www.ecoeduca.el)

Stop global warming. (Реклама компании Greenреасе)

Интересно, что маркетологи используют озабоченность людей климатическими изменениями на планете для рекламы своих товаров, например:

Stop global warming if уои like ice cream. (Реклама мороженого WALL'S)

Ещё одним словом, передающим тактильные ощущения теплоты, является heat. В словарных дефинициях находим семь значений данной лексемы - 1) the quality of being hot, 2) the energy that is produced when the temperature of something changes, 3) the heating system in a building, 4) strong and angry feelings, 5) a game or race at the start of a competition, 6) a source or level of heat for cooking, 7) pressure and criticism intended to force someone to do what you want.

Beat the heat in seconds. (Реклама кондиционеров Samsung)

В этом примере реализуется первое значение heat - the quality of being hot. Здесь рекламируется техническое устройство, кондиционер, для устранения некомфортного жаркого ощущения. Победа над жарой- главный определяющий фактор для покупателя.

В следующем объявлении рекламируются способы укладки волос, не требующие термического воздействия. Использование отрицания по гарантирует покупателю отсутствие неприятных ощущений.

10 no heat hairstyles for fall and winter (Реклама модных причёсок, theeverygirl.com)

Однако heat не всегда ассоциируется с неприятным, обжигающим ощущением. В рекламе обогревательных устройств реализуется значение the energy that is produced when the temperature of something changes, то есть способность вырабатывать и поддерживать тепловую энергию, что является привлекательным признаком для покупателя:

Heat holders. The ultimate thermal sock. (Реклама термоносков Sockshop)

Omni-heat reflective. (Реклама верхней одежљы Columbia)

My heat. (Реклама полов с подогревом, Electric underfloor heating сотрапy)

Master the heat at approx. 400 to 500 F. (Реклама кухонной плиты, Нy-Vee shop)

В нашем материале есть примеры использования heat в переносных значениях, так в объявлении Naked heat palette. (Реклама декоративной косметики Urban Decay) 
heat передаёт не температурные ощущения, а определенный набор цветов, так как рекламируется палетка теней для глаз с огненными и песочными оттенками

Приведем еще один пример переносного значения heat:

Feel the heat. (Реклама парфюмерной продукции Веуопсе Неat Perfume)

В данной рекламе парфюмерной воды heat реализует сему «чувственность», «nривлекательность», которая актуализируется благодаря сочетанию с именем известной сегодня на весь мир обладательницы мощного меццо-сопрано и яркой, роскошной внешности Вейонсе Ноулз. В этом случае авторы рекламного текста побуждают потребителя к покупке товара, акцентируя яркие и приятные ощущения, которые покупатель будет испытывать, пользуясь предлагаемым ароматом.

В примере Eat the heat! (Реклама кулинарного соревнования Chilli cook off contest) heat выражает значение «острый, перченый вкус». Посредством метонимии Попробуй острое! - учредители конкурса указывают на ожидаемый вкус блюд, которые предстоит приготовить участникам конкурса, и приглашают принять в нем участие.

Рассмотрим две производные от heat лексические единицы, которые встречаются в британской и американской рекламе, а именно глагол heat и существительное heating, которые также используются в рекламе систем отопления и оборудования для приготовления пищи. В проанализированных нами словарях зафиксированы следующие значения данных слов: heating - отопление и процесс нагревания - 1) equipment that produces the heat used for heating a building, 2) the process of making something warm; to heat - нагревать - 1) to make something hot, 2) to become hot $[13,14,15]$.

В большинстве случаев они употребляются в своем основном значении нагрева, отопления, подогрева:

Underfloor heating kits (Реклама полов с подогревом Radiant heating)

Cooling and heating problems?(Реклама технической компании Lanz Inc.)

Galaxy heating film. (Реклама отапливаемого оборудования Voltage carbon Fiber heaters)

Love keeps people close. Cold keeps them even closer. 8 million people suffer from the cold because they don't have the means to heat their homes. (Реклама благотворительного фонда Foundation Abbé Pierre)

Heat fast. Cook fast. (Реклама кукурузного масла Coroli corn oil)

Далее рассмотрим прилагательное hot. Consice Oxford English Dictionary, www.dictionary.cambridge.org и www.macmillandictionary.com $[13,14,15]$ предлагают следующие дефиниции hot - 1) very high in temperature 2) food with spices 3) involving strong emotions 4) exciting and interesting 5) very good/skilful/lucky 6) difficult, dangerous 6) involving sex 8) determined to do something 9) busy 10) stolen/being looked for 11) close to guessing something $[13,14,15]$

В рекламе hot часто передаёт прямое значение «very high in temperature» (горячий) и обозначает признак напитков, продуктов питания и приготовленных блюд, например горячих супов:

Hot chocolate drink. (Реклама какао Cосоа)

Hot idea! Hot Dr Pepper. (Реклама напитка Dr Pepper)

Cozy up your day. Hot cocoa. (Реклама кофе Starbucks coffee)

M'm! M'm! Good! Hot buttered soup. (Реклама супов Campbell's)

В рекламе острого соуса, приготовленного из перца чили, hot передаёт значение “food with spices”, что и является основной характеристикой товара:

It was born hot. (Реклама соуса Tabasco)

В рекламных текстах востребовано еще одно значение прилагательного hot, совершенно не связанное с температурными признаками - exciting and interesting, которое реализуется, как правило, в словосочетаниях hot sale, hot price, hot deal. 
Примечательно, что в русском языке в подобных сочетаниях также используется прилагательное горячий - «горячая распродажа», «горячее предложение» или «горячие скидки»:

\section{Hot sale! (Реклама интернет-магазина AliExpress) \\ Hot UK deals! (Реклама интернет-портала Google Chrome Web store) Hоt price! (Реклама интернет-магазина vectorstock.com)}

Таким образом, проведенный анализ позволил описать некоторые особенности функционирования английской лексики теплых температурных ощущений и установить, что слова, входящие в данную лексико-семантическую группу, как правило, используются как действенное средство обозначения приятных, привлекательных, полезных свойств товара и способствуют повышению прагматического потенциала рекламного текста.

$$
* * *
$$

1. Музыкант В.Л. Теория и практика современной рекламы. М.: Компания «Евразийский регион», 1998. C. 400

2. Лившиц Т.Н. Реклама в прагмалингвистическом контексте. Таганрог: Издательство Таганрог, 1999. C.5-6.

3. Котлер Ф. Основы маркетинга. - М.: 1992. С.1000. С. 646.

4. www.thinkwithgoogle.com.

5. Морозов А.Ю. Имидж в рекламе: опыт лингвистического исследования. Самара: ОФОРТ, 2012. С. 156.

6. Назайкин А.Н. Практика рекламного текста. М.: Брестом-Пресс, 2003. С. 320.

7. Урысон Е.В. Проблемы исследования языковой картины мира: Аналогия в семантике. - М.: Языки славянской культуры, 2003. С.223.

8. Тун Хуэй. Лексика с семантикой чувственного восприятия в произведениях Юрия Коваля, диссертация на соискание ученой степени к.ф.н.: Киров: 2017. С. 220.

9. Цзылинь М. Перцептивная лексика в рекламном тексте, автореферат дис. кандидата филологических наук: Воронеж: 2017. С. 23.

10. Спиридонов В.Ф., Фаликман М.В. Горизонты когнитивной психологии. Хрестоматия. М.: Языки славянских культур, 2012. С.19.

11. Бубырева Ж.А. «Анализ существительных тактильного и кинестетического восприятия (на материале русского, французского и английского языков)»//Научные ведомости Белгородского государственного университета. Сер. «Гуманитарные науки». 2011. №6 (101). Т.9. С. 105-111.

12. Варламов А.А., Иняшкин С.Г., Горбачева А.В., Семиреченко А.Н., Осадчий М.А., Русецкая М.Н. «Лексика и сценарии тактильного восприятия в аспекте создания исследовательского тезауруса». //Вестник Волгоградского государственного университета. Сер.2: Языкознание. 2019. Т.18. № 1. C.47-61.

13. Concise Oxford English Dictionary. New York: Oxford University Press, 2008. P. 1681.

14. www.dictionary.cambridge.org.

15. www.macmillandictionary.com.

16. www.lingvolive.com.

17. Киреев С.И. Дискурс и концептосфера социальной рекламы, автореферат дис. кандидата филологических наук: Волгоград: 2008 - С.22.

\section{Уразметова А.В., Яровая А.И. \\ Семантические особенности ойконимических прозвищ}

Башкирский государственный университет

doi: 10.18411/lj-04-2021-197

(Россия, Уфа)

\section{Аннотация}

В статье рассматриваются семантические особенности вторичных топонимических номинаций на материале названий крупнейших городов США. Проводится семантический и количественный анализ исследуемых единиц. Результаты исследования обобщены в диаграмме.

Ключевые слова: топонимика, ойконимия, семантика, семантический анализ, прозвища, США. 